\title{
Listening to Improvisation
}

\author{
CLÉMENT CANONNE[1] \\ STMS (CNRS-IRCAM-Sorbonne Université)
}

\begin{abstract}
Is there something peculiar in our appreciation of improvised music? How does knowing that the music we are listening to is improvised affect our experience? As a first step in answering these questions, I have conducted an experiment in which an audio recording of the very same piece of music - a saxophone/clarinet freely improvised duet - was presented to 16 listeners, either as an improvisation ("IMPRO" condition), or as the live performance of a composition for saxophone and clarinet ("COMPO" condition). Listeners were encouraged both to reflect on their listening experience and to describe in their own words the music they heard. First, evaluative judgments were strongly different in the two listening conditions: listeners approached the piece with specific sets of values in mind, by relying on different features or different kinds of criteria (aesthetic ones in the COMPO condition $v s$ ethical ones in the IMPRO condition) to ground their appreciative judgments. Second, and maybe more importantly, listening experiences were quite different in the two conditions: in the COMPO condition, the piece was more commonly experienced as a sonic product, with listeners paying great attention to the various acoustical effects achieved by the musicians and to the overall structure (or lack thereof); in the IMPRO condition, the music was often described as a kind of communicational or relational process, with descriptions that largely interweaved music-specific terms and more broadly social terms. Overall, this experiment shows that our listening experience can be dramatically affected by modal considerations, i.e., by how we think the music was produced. More specifically, it sheds some light on what constitutes the core of the aesthetic experience of improvisation by exhibiting what is centrally at play (and what is not) when we listen to collectively improvised music.
\end{abstract}

Submitted 2017 November 30; accepted 2018 April 16.

KEYWORDS: improvisation, empirical aesthetics, aesthetic appreciation, musical communication

\section{INTRODUCTION}

IS there something peculiar about our appreciation of improvised music? Does knowing that a given piece of music is improvised affect our aesthetic experience? Do we process the same musical features when we attend to an improvisation rather than to the performance of a preexisting composition? Answering these questions would constitute a crucial step in the construction of an aesthetic of improvisation.

Of course, philosophers of music have argued for a long time that improvised music tends to yield a specific listening experience, and that it would be a mistake to approach an improvisation in the same way as one listens to a carefully written composition (see, amongst others, Alperson 1984; Brown 1996, 2000; Day 2010; Hamilton 2000; Love 2016). True, there is little doubt that Ornette Coleman's Free Jazz does not provide the same aesthetic experience than Olivier Messiaen's Chronochromie, nor that the former should be approached in the same way as the latter; but is this the case because one is (for the most part) improvised and the other composed, or is it because the two pieces differ so wildly in terms of their musical properties?

Indeed, the possibility remains that perceiving a piece of music as an improvisation is not in any way different than perceiving the exact same piece as the performance of a preexisting composition. If what 
is aesthetically valuable in a piece of music can be detected merely by listening to it, in what we actually hear, then knowing that a piece of music is improvised or composed should not make any difference.

This position, known as aesthetic empiricism, [2] has been under attack for some time now, with arguments coming from both empirical psychology and philosophical aesthetics. Beyond the individual factors (e.g., age, gender, musical expertise, openness, neuroticism, conscientiousness, etc.) that may affect the way we experience a given piece of music (Greasley \& Lamont 2016), many empirical studies have shown the importance of external factors in our appreciation and evaluation of musical works. For example, Kroger and Margulis (2016) showed that listeners were respectively positively or negatively biased in their evaluations of a given musical performance if they were told that it was from a world-renowned musician or from a Conservatory student. Perhaps more interestingly for the case under consideration here, Steinbeis and Koelsch (2009) showed that listeners did not think of the music in the same way if they were told that they were listening to a man-made composition or to a piece of music generated by a computer; specifically, they showed that listeners were thinking more strongly about the composer's expressed intentions in the first case than in the second case. However, it is not clear how knowing that the music is improvised could affect our listening experience: will the music "sound" the same? Will we find it better or worse? Will we use the same criteria in our evaluation, only in a looser way, or will we be resorting to specific evaluative criteria?

Similarly, many philosophers of art (see for example Kendall Walton, 1970) argued that our aesthetic response is thoroughly determined by the artistic category under which we perceive a given artwork. Perceiving a work of art under the wrong category would lead us to misrepresent some of its essential features: perceived as a Calderian mobile, a cubist painting would appear as static or lifeless; perceived as a comedy, a heart-wrenching tragedy would become incredibly ironic, etc. However, "improvisation" is not really a category in the Waltonian sense, as it is probably not "perceptually distinguishable" (Laetz 2010, 291): one can improvise a piece in sonata form, a blues in B-flat or a prelude in the style of Debussy. In Walton's own terms, there are no standard, variable and contra-standard perceptual features that a priori characterize or define improvisation. In other words, it is not certain that there is a clear empirical, perceptual basis upon which we could easily discern between composed and improvised music, just by listening to the music itself (see Lehman \& Kopiez 2010, for an empirical study on this topic).

In the same perspective, contextualist arguments - which are often opposed to aesthetic empiricism - do not seem to apply here. Indeed, according to contextualism, the aesthetic character of a work of art depends on "the cultural context in which the work is created and through which it is constituted" (Levinson 2016, 2). But while improvised music and composed music typically emerge from distinct music-historical contexts, this is not necessarily the case, as one can attend to concerts in which, for example, musicians readily alternate between performances of written pieces from contemporary composers and free improvisations, the latter being sometimes almost indiscernible from the former. [3]

There is, however, one argument against aesthetic empiricism that is clearly relevant for the case under consideration. Davies (2004) convincingly showed with numerous examples that the history of production of a given work of art - i.e., how the work is generated, the nature of the creative process which underlies its production - plays an important part in our critical appreciation of it. For example, knowing that an artwork is a forgery seems to have an impact on the value we ascribe to such artwork, whether in terms of achievement properties (e.g., craftsmanship, skillfulness, etc.), or artistic properties (e.g., originality, influence, etc.). "Improvisation" is like "forgery", in the sense that it describes a certain mode of production: more specifically, it refers to artworks that are conceived in the same time as they are performed or crafted. If Davies is right - that the history of production of a given artwork does matter in our aesthetic appreciation - then listening to a piece of music as an improvisation should lead to a different experience than listening to a composed piece of music, all other things being equal. As Andrew Kania $(2008,76)$ puts it, "[since] it is even more difficult to improvise a good fugue [than to compose one], we tend to value equally good, but improvised, performances of fugues even more highly than those of "precomposed" fugues. If someone does not recognize that a certain performance is improvised, but rather assumes that it is a performance of a composed work, she will tend to undervalue the performance".

But apart from this evaluative component, which is undoubtedly an important aspect of our general response to art, it is not clear that such knowledge specifically alters the kind of aesthetic experience we have in perceiving an artwork; at least if, by aesthetic experience, we mean the sort of perceptual-imaginative experience elicited through attending to "an object's form and content and the relationship between them" (Levinson 2009, 21). Indeed, a perfectly forged visual artwork possesses, by 
definition, the same form, the same content and the same relationship between form and content than its model. As such, our aesthetic experience (understood in the somewhat restricted sense mentioned above) of the forged artwork should not be different from our aesthetic experience of its model: the gracefulness or the poignancy of a painting - and the effects such gracefulness or poignancy have on us - should be preserved in its perfect forgery.

One might wonder, however, if the same could be said of a composition and its improvised indiscernible counterpart. It seems there is an important difference between the painting/forged painting case and the composition/improvisation case. Improvisations and compositions do not only differ in terms of the manner of creative or generative processes taking place - what Lee B. Brown (1996) designates as modal factors - but also in terms of their ontologies. While painting and forged paintings both belong to the same ontological category of material artifacts, it is not obvious that composed musical works and improvisations belong to the same ontological categories: works of music are standardly conceived as more or less abstract sound structures (see for example Dodd 2007 or Levinson 1980), but improvisations are probably best described as sets of generative actions or performance events.

If improvisations and compositions are indeed apprehended under different ontological categories, this should be reflected in our aesthetic appreciation of improvisation, possibly in a way that goes beyond the mere evaluative aspect of our appreciation. Our initial question can then be reformulated in the following way: how does apprehending a set of musical sounds as generative actions, rather than as the exemplification of an abstract sound structure, affect the perceptual-imaginative experience we have when attending to music? Do we interpret musical sounds in the same way if we know they are improvised? Is the phenomenological experience we have when listening to improvised music the same as when we are attending to the performance of composed music?

\section{METHODS}

To answer these questions, I have designed a study to explore which aspects of our aesthetic experience of improvised music are specifically sensitive to modal factors (i.e., by how we think the music was generated), as independently as possible of the other factors (acoustical, categorical, contextual, etc.) that may be involved in our appreciation of improvised music. The general idea was then to present two groups of listeners with the exact same recording, described either as the recording of an improvisation or as the recording of the performance of a preexisting composition, and to compare the listeners' responses in these two situations (for the methodological advantages of such an experimental paradigm in investigating the role played by extrinsic factors in our appreciation of music, see Anglada-Tort \& Müllensiefen 2017). As a preliminary step, a pilot experiment was organized to select a piece that was sufficiently ambiguous to be able to pass as an improvisation or as a composition.

\section{Pilot Experiment}

\section{PARTICIPANTS}

Ten young adults (age $M=20.2, S D=2.36$; male $=6$ ) were recruited to participate in a pilot experiment. Participants were undergraduate students in composition from Lyon's Conservatory. All had a substantial level of musical training (at least 7 years of musical practice) and had followed an introductory class to improvisation as part of their curriculum.

\section{STIMULI}

Six instrumental duets of so-called "free improvisation" - as close as possible to improvisation in its "purest form" (Corbett 2016, xii) in the sense that they did not make any use of familiar pre-composed materials such as themes, chord progressions or formal schemes - were selected, based on my initial impression that they could pass as performances of a written composition, or at least not elicit a strong disbelief when presented as such to the listeners. The duets were all recorded in studio conditions and were of various durations (average duration $=5$ '27', the shortest being 3'54' and the longest 9'32'').

These improvised duets used instrumental techniques and musical material that resemble what can be heard in certain contemporary works of music (for example in the works from the likes of Frank 
Bedrossian or Raphaël Cendo), to prevent the participants answering based on the music being stylistically tied to well-known improvised musical traditions, like jazz or Indian Carnatic music.

Finally, the selected pieces were collective improvisations; an essential aspect of improvisational practices - and, presumably, of their aesthetic appreciation - is that improvisation is often a collective process (even if, of course, solo improvisations are not rare), and it seemed important to cover that aspect in the present study.

\section{PROCEDURE}

The participants were gathered in their usual classroom, and were told that they would listen to six audio recordings, reporting individually for each of them whether they thought the music was improvised or composed.

RESULTS

Table 1. Results of the pilot experiment

\begin{tabular}{|l|l|l|l|l|l|l|}
\hline & Duet \#1 & Duet \#2 & Duet \#3 & Duet \#4 & Duet \#5 & Duet \#6 \\
\hline Improvised & 9 & 7 & 9 & 6 & 8 & 10 \\
\hline Composed & 1 & 3 & 1 & 4 & 2 & 0 \\
\hline
\end{tabular}

As can be seen in Table 1, the duets were largely recognized as the improvisations that they were. Interestingly, there was almost no hesitation among the participants when it came to the high-energy duets (Duets \#1, \#3, \#5 and \#6) - perhaps because they heard them as more clearly related to a free jazz aesthetics - whereas opinions were more divided for the two slower and/or calmer duets (Duets \#2 and \#4), which contained fewer musical events. Duet \#4 was the object of a heated discussion between the participants in the collective debriefing that followed the listening session, a significant minority of participants pointing to certain musical features of the piece (e.g. the synchronization of the two instruments in some parts) to defend their opinion that it could not have been improvised.

\section{Main Experiment}

\section{PARTICIPANTS}

Sixteen adults participated in the main experiment. Since the main goal of this experiment was to gather precise phenomenological data on how the aesthetic experience of an improvisation and of a pre-composed piece of music might differ, it was important to recruit participants who were not only of high musical expertise, capable of commenting in detail on the music heard, but also well acquainted with both improvised music and contemporary classical music, to be able to at least minimally engage with the music (see Levinson 1990 on the role played by familiarity in aesthetic appreciation). All sixteen participants (age $M=35.1, S D=7.5$; male: 13) were thus musicians with at least 15 years of musical practice. Ten participants were graduates of Paris' Conservatory in both improvisation and classical instrumental performance and were active as performers of both improvised music and contemporary classical music; the other participants $(N=6)$ were members of the Orchestra of New Musical Creations, Experimentations, and Improvisations - a Paris-based ensemble dedicated to improvisation and contemporary music.

\section{STIMULI}

The piece used for the experiment was the Duet \#4 from the pilot experiment - a saxophone/clarinet improvised duet performed by Michel Doneda (saxophone) and Joris Rühl (clarinet), taken from their album Linge (Umlaut Records, 2012, Track 1, duration: 8'02') - as it was for this piece that opinions expressed by participants in the pilot experiment were most divided. Given its duration, only this one piece was selected for the experiment so that the listening sessions would not take an overly long time for the participants. 


\section{PROCEDURE}

Participants were welcomed individually in a comfortable listening room, and were told that they were going to hear a piece of music and would be asked to comment on it. Participants were randomly assigned to one of two groups: in the "IMPRO" condition (listener I1 to I8; $M=36$; male: 7), the piece was described as an improvisation recorded a few years ago, and in the "COMPO" condition (listeners $\mathrm{C} 1$ to C8, $M=34,1$; male: 6 ), the piece was described as the performance of a composition for saxophone and clarinet written a few years ago.

After their first listening of the piece, participants in both conditions were asked three questions: What did you think of the piece? Which aspects of the piece did you like, if any? Which aspects did you dislike, if any? They were then asked to listen to the recording a second time, and to stop the recording as soon as they remembered what they felt or thought when first hearing that very passage. In sum, participants were encouraged to both reflect on their listening experience and describe in their own words the music they heard. Participants' comments were made in a quasi-conversational setting, with myself acting as an interlocutor to provide follow-up or clarification questions when needed. The listening sessions lasted between 45 minutes and 1 hour 12 minutes.

\section{DATA ANALYSIS}

Listeners' comments were transcribed and analyzed using the grounded theory approach of constant comparison (Henwood \& Pidgeon 2004). Grounded theory analysis results in an interpretation of the data that can be taken to an abstract level but that is profoundly grounded on, and emergent from, the empirical data (Charmaz, 2006). In the present study, the focus was on identifying recurring themes and potential convergences between the listeners' testimonies, upon which further hypotheses about the aesthetic appreciation of improvisation could be developed. The first step was to code the transcribed listeners' comments, aiming at summarizing each segment of the data in as few words as possible. This resulted in 544 different statements (236 for the COMPO group and 308 for the IMPRO group). During this first step, I took notes as thematic connections started to emerge within each group of listeners' testimonies. In a second stage of the protocol, I generated abstract themes (e.g., "value," "form," "interaction," "intention," "clarity," "originality," "behavior", "instrument", etc.) that allowed me to synthetize and organize the data resulting from the previous line-by-line coding.

\section{RESULTS}

Two main results can be derived from the data analysis:

1. Evaluative judgments were strongly different in the two conditions:

a. Because aesthetical criteria relative to musical form were used in very distinct ways by COMPO listeners and IMPRO listeners;

b. But also because IMPRO listeners used specific evaluative criteria, superimposing ethical aspects on aesthetic ones in their apprehension of the music's "imperfections."

2. The phenomenology of the listening experience was quite distinct in the two groups, the piece being more commonly experienced as a sonic product in the COMPO condition while the music was rather described as a kind of communicational or relational process in the IMPRO condition.

\section{Apprehending Musical Form}

A striking result from this experiment is that evaluative judgments were strongly different in the two listening conditions. Out of the 52 evaluative statements made by COMPO listeners, 43 were negative, while in the IMPRO condition only 29 evaluative statements (out of 71) were negative. Simply put, when experienced as a composition, the piece was almost unanimously judged negatively while evaluations were generally more positive when the piece was experienced as an improvisation, although there was some degree of variability in the listeners' evaluations.

The main reason invoked to ground such negative judgments in the COMPO condition was that the piece was judged to be missing any kind of formal organization on a large time scale (20 statements made explicit reference to this point). More specifically, listeners seemed to strongly regret the episodic 
structure of the piece, the absence of a rhetorical or narrative organization, or simply the lack of a clear direction in the long run:

"I'm hearing blocks of sounds that are juxtaposed one after the other, there are not really strong connections between them. And all these successive musical moments are not integrated in an overall structure" $(\mathrm{C} 1)$;

"There is no overall conception on how to develop the musical material. The form is nothing else than a succession of episodes, that's not enough" (C3);

"The composer is in charge of creating a beginning, a middle and an end; here, it just feels like he's throwing his ideas one after the other" (C4);

"I had trouble hearing the form, there were not any signals or clear rhetorical markers" (C2);

"Maybe the piece adheres to an overall structure, but it's not very clear... Anyhow, the piece does not follow a discursive logic. There is no intention to narrate something: each musical object is encountered in its own situation but without any structural links with the other situations" (C1);

"I didn't understand the form, in the sense of a coherent temporal construct that is unfolding through time. It lacks a clear direction" (C7);

"There are a lot of variations on a short time scale but the overall form is surprisingly static, almost non-existent" (C5).

The highly episodic organization was also pointed out by the listeners in the IMPRO condition, but in most cases (10 out of 13 statements), this was perceived as a standard feature of improvisation and, as such, was not used to ground any negative judgments:

"I told myself that there was no pre-established form in this piece, there was a sort of "in-progress" quality to the music, as if the musicians were building the piece one sound after the other, one sequence after the other... which is not surprising since it's improvised!" (I6);

"The form is very linear...new ideas are found along the way and it changes the music bit by bit. So it's not very rich or interesting from a formal point of view but it's often like that in improvisation, that's not a real problem" (I4);

On the contrary, attempts made by the musicians to delineate a simple overall structure, whether by using silences to articulate successive sequences or by progressively transforming the initial musical material over the course of the piece, added to the piece's credit for certain listeners in the IMPRO condition:

"I think it's quite well done from a structural point of view. The overall progression is clear enough, you can easily follow the successive parts. And that's something that is not that easy to achieve in improvisation" (I2).

In that respect, clearly listeners were not expecting as much in the IMPRO condition compared to the COMPO condition, but that does not mean that the temporal unfolding of the music was of secondary importance in the IMPRO condition. After all, both composition and improvisation result in temporally organized musical sounds; as a result, it is not entirely surprising that, at a general level, shared criteria regarding the evolution of musical sounds through time should be used to evaluate both creative processes. [4] However, the comparison between the two conditions shows that these criteria were not applied on the same time scale: COMPO listeners were much more concerned with the temporal unfolding of the piece on a larger time scale than IMPRO listeners, who focused rather on what happened on a shorter time scale (e.g., fluidity of the transitions, clarity in the direction of a given musical gesture, unity of a short sequence, etc.). Overall, there were only 13 statements relative to large-scale organization in the IMPRO group, while 37 of their statements discussed the local organization of a given episode or sequence:

"I like how quickly the music shifts, here: there is a sudden rinforzando in the clarinet, the saxophone makes a glissando and, before we realize it, the music is already elsewhere" (I8);

"I really liked this crescendo, starting almost from nothing but clearly leading to this passage in the higher register" (I3); 
"In the first minute, there is only one idea, and they explore the different manners to play with that idea, it's very pleasant to follow" (I6).

More generally, while fluidity, tightness and consistency were taken as implicit norms of evaluation by the COMPO listeners - hence the very negative evaluations when they realized that the piece was not meeting these standards - they were only considered as ideal regulative objectives by the IMPRO listeners, something that the musicians should strive to achieve, while recognizing that they would fail to do so most of the time. However, when IMPRO listeners judged that the improvisers did meet these standards of fluidity, tightness and consistency, they praised the virtuosity and mental agility of the musicians who were no longer said to be improvising but rather "composing in real time" (i.e., improvising music that approached standards of perfection they did not routinely expect from an improvisation). In other words, one of the reasons the piece was judged as successful in the IMPRO condition was precisely that, in some respects, it could pass as a performance of a written composition - or, to emphasize the paradox, that it did no longer sound improvised:

"They're not simply improvising, it's like they're composing in real time, they're really trying to build a form. That's also what I like in this piece" (I8);

"When improvisation achieves results that seem to be only achievable in written music, for example when musicians are changing what they are doing in an almost perfectly synchronous way, I tend to be even more impressed by the musicians, and to feel an even greater pleasure" (I3); "If I didn't know it was improvised, I would really feel that it is written out, because everything is so sharp, so clear with one musician responding as soon as the other stops playing. It's almost as if it was planned, or as if the musicians were reading from a score" (I1).

\section{Imperfections, Improvised Feel, and the Ethical Appreciation of Improvisation}

The excitement expressed by listeners in the IMPRO condition when they felt that musicians approached the level of precision and fluidity more traditionally associated with the performance of composed musical works, or the fact that they used terms such as "miracle" or "magic" to describe these passages, are in fact quite revelatory of improvisation being apprehended against the backdrop of its own potential failure. Indeed, in many ways, so-called imperfections that were routinely encountered in the piece - technical failures, drops in inspiration, inconsistencies, etc. - appeared to play a central role in its appreciation under the IMPRO condition. Of course, that is not to say that the improvisation is valued because of its inherently imperfect state. To quote Andy Hamilton $(2000,171)$, it would probably be "overly paradoxical" to consider imperfection as an aesthetic value. Rather, the listeners' comments in the IMPRO condition tend to show that there is a complex relation, almost dialectical, between imperfection and the appreciation of improvised music.

On the one hand, because of the specificities of the creative process in improvisation - creating music on an instrument, without any pre-established plans, in the course of an irreversible performance IMPRO listeners were indeed expecting a certain number of imperfections in the resulting musical product, at least in regard to the norms of compositional practices (where one can plan ahead how the piece will unfold, modify at any time what is written without worrying at the same time about actually performing the piece); these imperfections were often regretted by the listeners but were nonetheless considered as "part of the trade" - a sort of necessary evil, the mark of "true" improvisation:

"This passage is maybe a little bit empty... it's often like that in improvisation, you just have to accept that some parts are going to be less successful than others. If that had been composed, I would have preferred that we skipped that part and that we arrived directly at that new part, with the softer sounds and higher pitches; but such exploratory passages where musicians give the impression of searching for a new idea are almost inevitable in improvisation" (I7);

"I really prefer the last third of the piece. It's more focused and they've found materials that work better together. If the music could have started there, it would have been really great; but hey, that's part of what improvisation is, there is often some trial and error before finding what to play" (I4). 
But, on the other hand, these imperfections were judged as contributing to the emergence of certain aesthetic properties - instrumental impulse, fragility, unpredictability, openness, urgency, etc. - that appeared to be valued intrinsically and which, taken together, seem to be integral to the music's "improvised feel". The constant presence throughout the piece of complex and unstable sounds, such as multiphonics, provides a nice example of this link between imperfection and improvised feel. While being a staple ingredient of pretty much every score written for wind instruments since the 1970's, complex multiphonics are often difficult to produce and even more difficult to sustain for a long time in a controlled way as sounds become more unstable and start to change abruptly, something which indeed happened at some points in the piece.

When the piece was apprehended as a composition, these moments of instability were clearly identified as mistakes, ascribed either to the performers, who were deemed unable to play correctly what was supposedly written, or, more often, to the putative composer, who was accused of writing something that is impossible to play for the performers, or putting too much emphasis on the technical and instrumental means of production, to the detriment of the musical substance per se:

"There are too many mistakes in the passage: I can guess what the composer's idea was but it's ruined by the performers who can't control their sound" (C6);

"To go from that noisy sound to that very high pitch, he chooses to use a harmonic sound; but it's a very bad idea, it's too demanding, no clarinet player has enough breath to sustain something like that for more than a few seconds!" (C5);

"The music is so much focused on instrumental technique... it's all you can hear. That's also why the form is episodic, because it's guided by the instrument: it's one technique after the other" (C1); "I found the piece a bit cold. It sounds like a technical study, where the composer tries to explore different instrumental techniques" (C7).

But these sounds were interpreted in a much more positive light by the listeners who attended to the piece as an improvisation, since they were then considered as part of the music's improvised feel; this may be because these sounds draw attention to the instrument and how the performer explores its possibilities, because they contributed to the piece's fragile and organic quality, or because they reinforced the music's unpredictability:

"I love the sound of the sax, here, it's so unique: you can really feel that they have practiced their instrument for twenty years, and that they have a way of using their instrument that is totally personal. You couldn't ask another saxophonist to play exactly like that, for example if you wanted to use that kind of sounds in a composition... it wouldn't work, it's really specific to improvised music" (I1);

"I love that this is not your typical sax sound; it's a very specific, individual sound that I must learn to know over the course of the performance... like discovering a new instrument" (I5);

"The music is organic because it is shaped by the musicians' breathing. When they are out of breath, the sound breaks... it's very fragile, very human" (I2);

"This rough multiphonic... it's not bad, this gives an organic quality to the music" (I4);

"I don't know if this sudden sound is voluntary or not. But in a sense, that does not matter. What is nice is that the musicians allow themselves to be surprised by their own sounds. When they play sounds like that, it's not always perfectly controlled, I guess. But they seize the opportunity to explore a new direction" (I7).

Overall, all 17 statements made by COMPO listeners referring to these specific sounds were negative statements, while 21 out of the 25 corresponding statements in the IMPRO condition were positive statements. How can we explain such a dramatic difference between the two conditions in the interpretation of these "imperfect" instrumental sounds? First, as said before, knowing that the piece was an improvisation strongly oriented the expectations of the IMPRO listeners; the imperfections they registered made sense to them because they were seen as deeply connected to the specificities of the generative process in improvisatory situations. In a sense, IMPRO listeners did expect some degree of instrumentdependency because, by definition, improvisation is always made with (or against) an instrument (including voice); they did expect some degree of formal indetermination because, by definition, it is generated without any pre-conceived plan; finally, they did expect some degree of fragility because, by definition, it 
is spontaneously generated, etc. In other words, they could integrate all these aspects into a coherent whole - an overall set of values and expectations - instead of being puzzled each time such an imperfection occurred, as was the case for the COMPO listeners.

Second, and maybe more importantly, IMPRO listeners' comments constantly oscillated between describing the music produced (in aesthetic terms of fragility, unpredictability, urgency, etc.), and characterizing the improvisers' actions (in terms of spontaneity, freedom, risk-taking, etc.). In other words, the listeners' appreciation in the IMPRO condition seemed to superimpose ethical aspects on aesthetic ones: through the resulting music, it was often the improviser's adhesion to the "regulative objectives" (Brown 2000) of improvisation that was appreciated. Describing a passage as "tense" or "fragile" could simply refer to the impression that the improvisers were taking a lot of risks in its realization; in other words, it was only described as tense because of the risk-taking involved, which explains why such aesthetic characterization simply disappeared in the description of the same passage in the COMPO condition:

"It's a bit like in poker: these sounds are very risky, because it can produce something awfully trivial, but if it works, the result is often excellent. I think you can really feel this tension here, it creates a certain fragility that is interesting" (I4);

"The sounds are really nice, very complex. But I don't know, something is missing... it's a bit too soft, there is not enough tension, not enough energy in this passage" (C4).

Conversely, when IMPRO listeners commented on the lack of unpredictability of the music, it was not so much as an aesthetic characterization (the sense of surprise, originality or uniqueness we expect from most artworks) but more to point out the improvisers' lack of spontaneity or freedom:

"I need to feel that the music can go anywhere, even if it actually stays in the same place. I need to feel that the musicians are free. But here, after a few minutes of listening, I just know that they will continue to play in the same framework, as if they were imprisoned in something established before they started to improvise and that they were unable to go off-track" (I5).

Musical "imperfections" were then also valued because they served as acoustical proofs of the musicians' sincerity and of the improvisation's authenticity - proofs that the music was in fact improvised, with musicians using these imperfections as a springboard to display their ability to improvise, understood as the ability to react in relevant ways to unexpected events (for example by immediately responding to a flaw in the production of a given note). This aspect was clearly identified by several listeners as an important part of the pleasure taken in listening to an improvisation:

"I really love those small moments in improvisation: here, the clarinet's sound is breaking, but somehow the musician integrates that in his playing, by producing a kind of tremolo" (I3);

"I want to see how the musicians manage to continue when something goes wrong, that's always exciting. I'm here to see the musicians at work!" (I8);

"When I'm listening to an improvisation, I want to see how the musicians will cope with their problems; it's not really the same with composition, it's more comfortable, usually the problems are already solved before the performance!" (I1).

In short, while musical imperfections appeared to systematically prevent COMPO listeners in appreciating the piece, they played a central role in IMPRO listeners' appreciation, by confirming the improvisation's authentic status, fuelling the emergence of certain aesthetic properties, and providing more occasions for the listeners to apprehend (and possibly enjoy) the improvisers' real-time musical thinking:

"Part of the pleasure I take in listening to this music is also to follow the musician's thinking, to track his choices in real time" (I7);

"Here, I think there is an unexpected pause, which occurs because the two musicians breathe at the same time, and it's breaking a little bit the music's rhythm and energy. But instead of taking advantage of this coincidence to introduce a new idea, the saxophonist just repeats what he was doing before... it's not a smart move! I'm more excited when I can feel the improviser's intelligence, his sense of timing" (I6); 
"I like imagining what the musicians are thinking: What are they trying to do? Why did they play that? Where do they want to go? That's the kind of stuff that I like about improvisation. And in the beginning, I thought it was very clear, that you could really follow what they were thinking" (I1).

\section{A Relational Experience}

Beyond the question of different values underlying the appreciation of improvisation and composition, the most striking result from this study is that people did not seem to listen in the same way across the two conditions. Of course, that does not mean that the musical sounds were totally different to their ears: in both conditions, the acoustical quality of the sounds produced by the performers was described in similar terms ("abrasive" (C3); "distorted" (I5); "harsh" (I1); etc.); similar images or metaphors were used to describe their iconic contents ("it sounds like a boat leaving the port" (C1); "it sounds like big machines spinning in the wind" (I2); "it sounds like elephants" (C5); etc.); and similar associations were suggested ("it sounds a bit like Pygmy polyphonies" (C2); "it's almost like an ethnic music" (I7); "sometimes the music is evocative of an exotic imagery, maybe African" (I4); etc.). But, in the IMPRO condition, the musical sounds produced by the performers seemed to acquire a whole supplementary layer of meaning, which dramatically altered the way listeners experienced the piece.

As one could expect, in the IMPRO condition, the music was perceived as a collective creative process - two musicians taking decisions in real time - rather than as the definitive product of a single mind.

"Naturally, when I'm listening to this, I'm more sensitive to the process, how the music is building, one moment after the other; there is no one overarching thought at work, here" (I7);

"The music is really being made by two people, in the sense that what you hear is the result of their interactions, the interferences that are produced by the encounters of their sounds" (I2).

As a result, for the listeners in the IMPRO condition, perceived sounds were not just sounds simpliciter, at least not all the time; they were also perceived as intentions-in-sounds. The sounds produced by the musicians were heard as both the finality of the creative process and the mean through which the collective process was brought forward - i.e., the means through which the musicians communicated and interacted with each other. In other words, the sounds produced by the performers were not only apprehended for their "acoustical" content or for the role they play in the overall form, but also for their "communicational" or "intentional" content, and what they revealed about their producer's current intentions in the collective music-making process. For example, towards the end of the piece, the saxophonist played a new, quasi-vocal, type of sound for a very short period of time. The 7 COMPO listeners who discussed the passage were perplexed by this event, treating it as another inconsistency; they did not understand why the composer used a totally new kind of sound one minute before the ending, nor why he chose a type of sound that blended so poorly with that played by the clarinet:

"I don't understand why the composer chose to use that kind of sound here; that's something we've never heard before and, if I remember correctly, it will not be developed further before the end of the piece. To me, that does not make any sense!" (C5).

On the contrary, in the 5 statements discussing that passage, IMPRO listeners ascribed a clear communicational content to that sound, interpreting it as a means for the saxophonist to nudge the clarinetist towards changing what she was doing:

"Here, the music is a bit monotonous, it's been the same thing for too long, now. The saxophone player tries to bring something different so that a new part can begin but it seems that the other musician ignores him and it just fails" (I3);

"The saxophonist is trying something new, I like this sudden agitation which shakes things up a little bit, it was necessary, I think, but I guess the clarinetist didn’t get what he was up to" (I4).

This difference in apprehending musical sounds led to two radically distinct experiences. In the COMPO condition, the piece was experienced as a sonic product, with, as discussed earlier, listeners 
paying great attention (in 71 of their statements) to the various acoustical effects achieved by the musicians and to the overall structure (or lack thereof):

"I've tried to follow the evolution of pitches throughout the piece, but the transformations in timbre were much more prominent" $(\mathrm{C} 2)$;

"The overall idea of this part is quite clear: making the acoustical material more and more granular. But there, it's done too quickly, and I wasn't able to clearly apprehend the successive steps of the process" (C3).

But in the IMPRO condition, the music was not just an affair of instruments, pitches, durations and timbres; it was also an affair of intentions, attitudes and interactions. As such, it was more commonly described as a kind of relational process, with the listeners dedicating 61 of their statements to the description of the specific dialogic relation embodied in this improvisation, to the quality of the listening the musicians gave to each other or to the efforts they did (or did not) make to accommodate each other's (sometimes distinct) artistic personalities:

"They're really into a kind of mimicry, because they play with the same type of musical sounds. But at the same time, each musician is also trying to affirm his own identity" (I1);

"I like how the musicians interact, it's a bit strange, it's neither a dialogue nor a superposition of monologues. When I'm listening to this, I imagine two people talking to each other while not really listening to the other... and while still managing to say more or less the same thing" (I2);

"I would say that what I like in this passage, and maybe generally in this improvisation, is that there is a mix between a desire for a fusional relationship and the denial of such a relationship... a kind of dance between attraction and repulsion: on the one hand, they try to blend their sounds but on the other hand, they do so in a too brutal fashion for the sounds to actually blend" (I3);

"It's a kind of dialogue, a dialogue made with held tones... It's almost as if the two discourses were parallel and independent from each other but at the same time, they're stopping when the other is stopping, they're listening to each other. Their relation is really interesting, both disinterested and caring, making the effort to join the other in a common sound, but at the same time with a strong sense of their autonomy. That's what I find the most interesting in this recording" (I5);

"What I hear above all in this piece is two individuals with very different personalities trying to communicate and to co-exist in the same space. And when I'm listening to their piece, what I'm really attending to is the dynamics of these relations - how the space between these two individuals shifts in the course of the performance" (I6).

Such descriptions, which interweave music-specific terms and more broadly social terms, were never made in the COMPO condition; and even when the dialogic quality of the music was mentioned, it was never in such strong socio-relational terms. In short, a striking specificity of the IMPRO condition was that the piece was also crucially experienced as the sonic embodiment of socio-musical relations.

\section{DISCUSSION}

The listeners involved in the present study clearly had a very different aesthetic experience depending on whether they approached the piece as an improvisation or as the performance of a pre-existing composition. Of course, one should keep in mind the limited generalizability of this result: it remains a possibility that the differences observed between the two groups of listeners are due to the specificities of the piece that was selected for the study, or to the fact that the piece was an actual improvisation rather than the performance of a pre-existing composition. As such, further studies will have to confirm this result by having participants listen to both compositions and improvisations, with a much greater stylistic variety. In addition, it would be interesting to gather quantitative data, for example by having the listeners rate each piece according to different dimensions (expressivity, predictability, performers' skill, formal organization, clarity of ideas, coherence between the instrumental parts, etc.); this methodology would also help avoiding potential demand biases that are inherent to the interview method that was used in this study. Nevertheless, I believe that, despite its exploratory nature, the present experiment allows us to gather some crucial insights on the nature of the aesthetic experience of improvised music. 
First, having the two groups of participants listening to the same recording made it possible to separate modal factors (i.e., hearing a piece of music as an improvisation or as a composition) from categorical and contextual factors (i.e., hearing a piece of music as jazz music or as western classical music). The differences observed between the two groups of participants were not attributed to listening to different genres of music or to music created in different socio-cultural contexts, but to the different beliefs they held on how the music had been generated. In other words, the comparison between the listeners' testimonies under the two conditions seems to show that there is something specific at play when we listen to a piece of music as an improvisation, regardless of the specifics of the music we are attending to. Of course, in both conditions, the piece was not only perceived as produced in a certain way (i.e., improvised or composed); it was also inevitably perceived as belonging to a certain artistic category (e.g., "arte povera," "noise music," "reductionism," etc.) and to a certain music-historical context (i.e., art-music from the beginning of the $21^{\text {st }}$ century). While "improvisation" and "composition" conceived as abstract modes of production may not be historic-artistic categories per se, their concrete incarnations are. As such, many of the comments made by the listeners on the piece (for example regarding its originality or lack thereof) were in fact commentaries on how the piece relates to specific musical genres (with their implicit or explicit stylistic norms, their archetypal features, etc.), and more generally to the current context of musical creation. However, even when modal, categorical and contextual considerations were largely intertwined in the listeners' responses, the systematic comparison of the data from the two conditions made it possible to single out the aspects of their responses that were more clearly directed towards modal factors rather than categorical or contextual factors.

Second, this experiment clearly showed that the specificities of the experience of improvisation should not only be defined in negative terms but also in positive terms. If the experience of IMPRO listeners differed from that of COMPO listeners, it is partly because the former tend to be more lenient in the way they apply certain evaluative criteria. But more strikingly, their experiences differed in the way they construed the sounds they heard: IMPRO listeners tended to adopt a specific listening behavior, in which the musical sounds were apprehended (at least partly) for their intentional and relational content something that was absent in the COMPO group. In a way, then, IMPRO listeners heard something more than COMPO listeners.

On a more general level, the present experiment confirms once again that the information the listeners receive before hearing a piece of music can significantly alter their experience (see Anglada-Tort \& Müllensiefen 2017; Kroger \& Margulis 2016); this information can not only bias their evaluation but, more interestingly, prompt them to adopt specific listening behaviors, ultimately leading to different aesthetic qualities being ascribed to the music heard.

It would be interesting to compare this data to François Delalande's study on listening behaviors (Delalande 1998). Delalande found that his participants tended to adopt one of three main listening behaviors when attending to a piece of electroacoustic music by Pierre Henry: taxonomic listening, which, in Delalande's own words, "responds to the listener's desire to have a global, synoptic vision of the work" (26) (and which was clearly the main behavior adopted by listeners in the COMPO condition); empathic listening, where "the listener is attentive to sensations, which are spontaneously described as the "physiological" product of the sound" (37); and what he calls "figurativisation," where "the listener tends to find the "figurative" in music or, more precisely, tends to think that certain sounds evoke something that moves, ultimately living" (47). It is not clear however that the "intentional" or "relational" listening behaviors adopted by the musicians in the IMPRO condition, where sounds are interpreted against the backdrop of the thought processes of their creators and of their socio-musical interactions, could fit in the tripartite model of listening behaviors suggested by Delalande. Listeners were not just imagining living beings or abstract agents in the music; they were actively perceiving the sounds as direct communicative acts (the intentional use of musical sounds by performers), from which they inferred the piece's broader relational content.

It is likely that this "intentional/relational" listening behavior is the result of what Lee B. Brown (1996) calls the presence of improvisation - improvisation being standardly experienced by the audience in the same time as it is created - and that it is therefore quite specific to musical practices that are, at least to some extent, improvisatory. We could go one step further and suggest another tripartite model linking typical listening behaviors to the degree of presence of the musical object: "acousmatical" listening where sounds are apprehended for themselves, independently of their actual source - for electroacoustic music; "instrumentalist" listening - where sounds are interpreted against the backdrop of their actual means 
of production - for performances of musical works; and "intentional" listening - where sounds are apprehended as the results of a generative musical thought - for improvised music.

At the very least, the present study suggests that there is a deep connection between ontology and aesthetics, and that our appreciation is thoroughly shaped by the ontological category under which we perceive the music we are listening to. Listening to music as something that people $d o$ is definitely not the same as listening to music as an abstract sound sequence encoded in a written score (on this topic, see Cook 2013 and Moran 2014). Listening to music as full-fledged human actions, that involve both body and mind, intra-personal and inter-personal expression, imperfection and moments of grace, gives rise to a specific type of subjective experience, one that highlights the deep ethical resonance that music can have in our lives and reminds us that there is much beauty to be found in the fragility of our endeavors and in the complexity of our relations to others. [5]

\section{ACKNOWLEDGMENTS}

This article was copyedited by Scott Bannister and layout edited by Kelly Jakubowski.

\section{NOTES}

[1] Correspondence can be addressed to: Clément Canonne, IRCAM, 1 place Igor Stravinsky, 75004 PARIS, canonne@ircam.fr.

[2] For a discussion of the different formulations of aesthetic empiricism see Lamarque (2010).

[3] It is for example the case of the concerts of the French ensemble ] $H$ [iatus, where no program is provided at the beginning of the concert, the audience being left wondering which piece was improvised and which was composed.

[4] See Levinson (1998) for a discussion of the principles grounding our evaluation of music.

[5] See Hagberg (2009) for similar insights.

\section{REFERENCES}

Alperson, P. (1984). On Musical Improvisation. The Journal of Aesthetics and Art Criticism 43, 17-29. https://doi.org/10.2307/430189

Anglada-Tort, M., \& Müllensiefen, D. (2017). The Repeated Recording Illusion: The Effects of Extrinsic and Individual Differences Factors on Musical Judgments. Music Perception 35, 94-117. https://doi.org/10.1525/mp.2017.35.1.94

Brown, L. B. (1996). Musical Works, Improvisation, and the Principle of Continuity. The Journal of Aesthetics and Art Criticism 54, 353-369. https://doi.org/10.2307/431917

Brown, L. B. (2000). "Feeling My Way": Jazz Improvisation and Its Vicissitudes. A Plea for Imperfection. The Journal of Aesthetics and Art Criticism 58, 113-123. https://doi.org/10.2307/432090

Charmaz, K. (2006). Constructing Grounded Theory. A Practical Guide Through Qualitative Analysis. Thousand Oaks: Sage Publishing.

Cook, N. (2013). Beyond the Score: Music as Performance. Oxford: Oxford University Press.

Corbett, J. (2016). A Listener's Guide to Free Improvisation. Chicago: The University of Chicago Press. https://doi.org/10.7208/chicago/9780226347462.001.0001

Day, W. (2010). The Ends of Improvisation. The Journal of Aesthetics and Art Criticism 68, 291-296.

Delalande, F. (1998). Music Analysis and Reception Behaviours: Sommeil by Pierre Henry. Journal of New Music Research 27, 13-66. https://doi.org/10.1080/09298219808570738 
Dodd, J. (2007). Works of Music: An Essay in Ontology. Oxford: Oxford University Press. https://doi.org/10.1093/acprof:oso/9780199284375.001.0001

Greasley, A., \& Lamont, A. (2016). Musical preferences. In S. Hallam, I. Cross, and M. Thaut (Eds.), Oxford Handbook of Music Psychology (2nd ed., pp. 263-281). Oxford: Oxford University Press.

Hagberg, G. (2009). Jazz Improvisation and Ethical Interaction: A Sketch of the Connections. In G. Hagberg (Ed.), Art and Ethical Criticism (pp. 259-285). New York: Wiley.

Hamilton, A. (2000). The Art of Improvisation and The Aesthetics of Imperfection. British Journal of Aesthetics 40, 168-185. https://doi.org/10.1093/bjaesthetics/40.1.168

Henwood, K., \& Pidgeon, N. (2004). Grounded theory in Psychological Research. In P. M. Camic, J. E. Rhodes, and L. Yardley (Eds.), Qualitative Research in Psychology: Expanding Perspectives in Methodology and Design (pp. 131-156). Washington, DC: American Psychological Association.

Kania, A. (2008). Piece for the End of Time: In Defence of Musical Ontology. British Journal of Aesthetics 48, 65-79. https://doi.org/10.1093/aesthj/aym040

Kroger, C., \& Margulis, E. H. (2017). "But They Told Me It Was Professional": Extrinsic Factors in the Evaluation of Musical Performance. Psychology of Music 45, 49-64. https://doi.org/10.1177/0305735616642543

Laetz, B. (2010). Kendall Walton's “Categories of Art”: A Critical Commentary. British Journal of Aesthetics 50, 287-306. https://doi.org/10.1093/aesthj/ayq017

Lamarque, P. (2010). Work and Object: Explorations in the Metaphysics of Art. Oxford: Oxford University Press. https://doi.org/10.1093/acprof:oso/9780199577460.001.0001

Lehmann, A. C., \& Kopiez R. (2010). The difficulty of discerning between composed and improvised music. Musicae Scientiae 14, 113-129. https://doi.org/10.1177/10298649100140S208

Levinson, J. (1980). What a Musical Work Is. The Journal of Philosophy 77, 5-28. https://doi.org/10.2307/2025596

Levinson, J. (1990). Musical Literacy. The Journal of Aesthetic Education 24, 17-30. https://doi.org/10.2307/3332852

Levinson, J. (1998). Evaluating Music. In P. Alperson (Ed.) Musical Worlds: New Directions in the Philosophy of Music (pp. 93-108). University Park: Pennsylvania State University Press.

Levinson, J. (2009). The Aesthetic Appreciation of Music. British Journal of Aesthetics 49, 415-425. https://doi.org/10.1093/aesthj/ayp043

Levinson, J. (2016). Aesthetic Pursuits. Oxford: Oxford University Press. https://doi.org/10.1093/acprof:oso/9780198767213.001.0001

Love S. C. (2016). The Jazz Solo as Virtuous Act. The Journal of Aesthetics and Art Criticism 71, 61-74. https://doi.org/10.1111/jaac. 12238

Moran, N. (2014). Social Implications Arise in Embodied Music Cognition Research Which Can Counter Musicological "Individualism”. Frontiers in Psychology 5, 676. https://doi.org/10.3389/fpsyg.2014.00676

Steinbeis, N., \& Koelsch S. (2009). Understanding the Intentions Behind Man-Made Products Elicits Neural Activity in Areas Dedicated to Mental State Attribution. Cerebral Cortex 19, $619-623$. https://doi.org/10.1093/cercor/bhn110

Walton, K. (1970). Categories of Art. The Philosophical Review 79, 334-367. https://doi.org/10.2307/2183933 